\title{
Ki-67 Prognostic Value in Different Histological Grades of Oral Epithelial Dysplasia and Oral Squamous Cell Carcinoma
}

\author{
Amer Takkem ${ }^{1 *}$, Charif Barakat ${ }^{1}$, Safa Zakaraia', Khaled Zaid ${ }^{1}$, Johnny \\ Najmeh$^{2}$, Mahdi Ayoub ${ }^{3}$, Mohammad Yaman Seirawan ${ }^{4}$
}

\begin{abstract}
Introduction: Abnormal cell proliferation appears to be a possible predictor of tumorigenesis, Ki-67 protein expression is closely related to the cell proliferation and could be used as a biomarker for the growth in the most of human tumors. The aim of the study: Investigating of Ki-67 expression in the pathological grades of oral epithelial dysplasia and oral squamous cell carcinomas. Materials and Methods: The sample consisted of 30 formalin-fixed, paraffin-embedded specimens of oral epithelial dysplasia (OED), 30 other of oral squamous cell carcinomas (OSCC), and 10 normal oral epithelium (NOE) were conventionally stained with hematoxylin and eosin and immunohistochemically stained with Ki-67 monoclonal antibody. Results: Expression of Ki-67 was restricted to the basal layers in the normal oral epithelium whereas Ki-67 positive cells in oral epithelial dysplasia (OED) were located in the basal, suprabasal and spinous layers, Ki-67 expression was increased in high-risk cases. Ki-67 positive cells in well-differentiated (OSCC) were located mainly in the periphery of the tumor nests, in moderately-differentiated (OSCC) were located in both peripheral and part of a center of the tumor nests whereas it was diffused in most of the Poorly-differentiated (OSCC). Statistical analysis indicated a significant difference between the expression in (OED) and (NOE), (OSCC) and (NOE), and no differences between (OED) and (OSCC). Conclusion: This study has concluded that Ki-67 antigen could be used as a marker for the histological grading of OED and OSCC, Expression of Ki 67 increased according to the severity of oral epithelial dysplasia.
\end{abstract}

Keywords: Ki-67 antigen- Oral epithelial dysplasia (OED)- Oral squamous cell carcinomas (OSCC)- NOE

Asian Pac J Cancer Prev, 19 (11), 3279-3286

\section{Introduction}

Precancerous lesions of the oral cavity present as visibly abnormal areas of oral mucosa and may be a source of anxiety for the patient and the clinician. precancerous lesions should be biopsied to evaluate for oral epithelial dysplasia (Panwar et al., 2014). There are multiple genetic mutations that must occur for normal tissues to progress to dysplasia or squamous cell carcinoma. Biopsy remains the gold standard for the investigating for Oral epithelial dysplasia and oral squamous cell carcinoma (Mutalik et al., 2014; Boeve et al., 2018). Two common conditions of precancerous lesions were included in the current study; leukoplakia and erythroplakia.

Oral leukoplakia is a white patch on the mucosa, which cannot be scraped off and cannot be attributed to any other disease process. 'Leuko' means white and 'plakia' means patch (van der Waal, 2018). The rate of malignant transformation is higher in non-homogenous Oral leukoplakia, lesions that demonstrate moderate to severe dysplasia and lesions on the tongue or floor of the mouth,
Lesions $>200 \mathrm{~mm}^{2}$, age $>60$ years and smokers are also more frequently associated with malignant transformation (Ho et al., 2012). The presence of oral epithelial dysplasia is the strongest indicator of malignant transformation with rates quoted between 15-30\% (Kumar et al., 2013; Warnakulasuriya et al., 2007). Speckled leukoplakia, which is characterized by the presence of white and erythematous nodular patches areas were often associated with oral epithelial dysplasia or OSCC (Pindborg et al., 1963; Liang et al., 2017).

The term epithelial dysplasia is a histopathologic diagnosis rendered when cells with atypical morphology are detected within the epithelium and are graded by severity as mild, moderate, or severe dysplasia or carcinoma in situ (Rhodus et al., 2014). Oral epithelial dysplasia is histologically characterized by a stratified squamous epithelium is characterized by cellular atypia and loss of cell differentiated and stratification (Warnakulasuriya et al., 2008).

In oral epithelial tissues, accumulating mutations, chromosomal damage, and loss of cellular control

${ }^{1}$ Department of Oral Histology and Pathology, ${ }^{2}$ Department of Periodontology, ${ }^{4}$ Department of Endodontics and Operative Dentistry, Faculty of Dentistry, University of Damascus, Damascus, Syria, ${ }^{3}$ DESS Dental Public Health, Lebanese University, Beirut, Lebanon.*For Correspondence: dramer.takkem@gmail.com 
functions, these changes are manifested as the transition from normal histology to dysplasia, to superficial cancer and invasive squamous cell carcinoma (Muller, 2018).

Correct diagnosis of precancerous lesions with high risk of malignant transformation may help to Perform appropriate treatment. Most Oral Squamous Cell Carcinoma progresses via a premalignant lesion called dysplasia (Conway et al., 2015). Clinicopathologically, malignant transformation of oral precancerous lesions is observed at a frequency up to $17.5 \%$ (Hwang et al., 2018).

Squamous cell carcinoma is the most common oral cavity cancer. It is the eight most common cancers in men and fifth most common in women (Zaid, 2014). Oral squamous cell carcinoma (OSCC) is more commonly noted in men usually above 40 years of age (Sasaki et al., 2005). OSCC may affect any site in an oral cavity, but most frequently the tongue and the floor of the mouth (Khammissa et al., 2014). The main risk factors associated with Oral squamous cell carcinoma include tobacco/ betel/ areca nut use, alcohol consumption, infection with high-risk human papillomavirus (HPV) genotypes, and a diet low in fruits and vegetables (Feller and Lemmer, 2012; Zaid et al., 2016). Oral Squamous Cell Carcinoma is a malignant tumor derived from the stratified squamous epithelium of the oral mucosa (Tumuluri et al., 2002). Various histopathological grading systems of OSCC have been discussed in literature and Broder's grading has been popular for a long time. Broder's criteria to classify as well-differentiated squamous-cell carcinoma (WDSCC), moderately differentiated squamous-cell carcinoma (MDSCC) and poorly differentiated squamous-cell carcinoma (PDSCC) (Rajendran, 2006; Rahaman and Mujib, 2014).

The WHO expects a worldwide rising oral squamous cell carcinomas (OSCC), In the US, OSCC represents $2 \%-4 \%$ of the annually diagnosed malignancies, being responsible for 8,000 deaths every year (Scully, 2000). Despite refinement of surgical techniques in the past few decades once invasive cancer is formed, the prognosis is poor with an average 5-year survival rate of $40 \%$ of affected patients (Wang et al., 2013; Vigneswaran and Williams, 2014; Jeon et al., 2017).

Markers of proliferation could potentially be good candidates for improving the prognostic evaluation of premalignant lesion and OSCC. until now, a panel of molecular markers has not been determined that allows for a prognostic prediction of oral squamous cell carcinoma. However, these new markers could be considered complementary to conventional prognostic evaluation (Monteiro de Oliveira Novaes and William, 2016).

The control on cell proliferation biological process is thought to be lost in cancer (Tumuluri et al., 2002), and many studies have reported that abnormal cell proliferation appears to be a precursor and may be a predictor of tumorigenesis (Gavish et al., 2016; Bacchi and Gown, 1993). The most common immunohistochemical markers used to study cell proliferation are proliferating cell nuclear antigen Ki-67 antigen (Malecki et al., 2012).

The Ki-67 protein, which encodes two protein isoforms with molecular weights of 345 and $395 \mathrm{kDa}$, was identified by Scholzer and Gerdes in the early 1980s
(Scholzen and Gerdes, 2000). The Ki-67 protein has a half-life of $\sim 1-1.5$ hour, it is present during all active phases of the cell cycle (G1, S, G2, and M), but is absent in resting cells (G0) (Hooghe et al., 2008; Shirendeb et al., 2009). In later phases of mitosis (during anaphase and telophase), a large decrease in Ki-67 levels occurs (Modlin et al., 2008). Human Ki-67 is a 3256-amino-acid protein recognized by a monoclonal antibody generated by injecting mice with nuclei isolated from Hodgkin lymphoma cells (Gerdes et al., 1983). Major regions of the $\mathrm{Ki}-67$ protein include; an N-terminal forkhead-associated (FHA) domain; a protein phosphatase (PP)1 binding domain; a large unstructured central region comprising 16 tandem repeats of 122 residues (in primates); and a C-terminal LR (leucine/arginine-rich) chromatin-binding domain (Nagao et al., 2017). The function of the repeats, which are encoded by a single huge exon, remains unclear. $\mathrm{Ki}-67$ redistributes from the nucleolar cortex and dense fibrillar compartments during interphase (MacCallum and Hall, 2000), to the chromosome periphery during mitosis (Takagi et al., 2016).

Critically, the antigen is not detected in noncycling cells. Ki-67 is highly abundant and the epitope recognized by the Ki-67 monoclonal antibody (FKELF) is naturally amplified, being present on nine of the $16 \mathrm{Ki}-67$ repeats that comprise much of the polypeptide (Booth and Earnshaw, 2017). These features make Ki-67 one of the best markers to assess cell proliferation (Whitfield et al., 2006) and it is used as a reagent to aid in determining a patient prognosis for several tumor types, including breast cancer (Yerushalmi et al., 2010; Dowsett et al., 2011).

The prognostic value of Ki-67 protein has been investigated in a number of studies with its potential as a reliable marker having been shown in cancers of the breast, soft tissue, lung, prostate, cervix and central nervous system (Sorbye et al., 2012; Josefsson et al., 2012; Ishihara et al., 2013). It has been shown that blocking of $\mathrm{Ki}-67$ protein either by microinjection of antibodies leads to inhibit the progression of the cell cycle (Li et al., 2015). An increasing number of studies have suggested that Ki-67 protein may be an important factor in cancer grading and prognostic evaluation (Li et al., 2015).

The aim of this study was to identify an association between Ki-67 protein expression and histological grades of oral epithelial dysplasia - oral squamous cell carcinomas. And the role of Ki-67 protein in the prognostic of different histological grades of oral epithelial dysplasia and oral squamous cell carcinomas.

\section{Materials and Methods}

The sample consisted of 30 formalin-fixed, paraffinembedded blocks of Oral epithelial dysplasia (OED), 30 other of oral squamous cell carcinomas (OSCC), and 10 normal oral epithelium (NOE) were collected from archival files of The Damascus University. Clinicopathologically, the age range of the 70 patients was from 20 to 75 years (average 40 years), the sex ratio was 1:1.

Oral epithelial dysplasia (OED) was subdivided into 10 mild OED, 10 moderate OED, 10 severe OED. Oral squamous cell carcinoma (OSCC) was subdivided into 10 
well-differentiated OSCC, 10 moderately -differentiated OSCC, 10 poorly-differentiated OSCC.

Paraffin sections of formalin-fixed tissues were used for both histological and immunohistochemical evaluation. Hematoxylin and eosin stained sections of 4 $\mu$ were used for routine histological examination.

\section{Immunohistochemistry (IHC)}

Immunohistochemical (IHC) detection of Ki-67 was performed using DAKO-LSAB-2HRP detection system. For IHC staining the sections were cut at approximately 4 $\mu \mathrm{m}$ thickness using rotatory manual microtome. For IHC, sections were placed on pre-coated slides and incubated for $1 \mathrm{~h}$ at $60^{\circ} \mathrm{C}$ in an incubator.

For antigen retrieval, the sections were placed in a $1 \mathrm{mM}$ citrate buffer $(\mathrm{pH} 6)$ and microwave was used with cycles of high, medium high, low and very low each lasting for $5 \mathrm{~min}$ and then cooled to room temperature. The endogenous peroxidase activity was blocked with $3 \%$ hydrogen peroxide for $10 \mathrm{~min}$ followed by washing in $0.05 \mathrm{mMTris}$-buffered saline (TBS) at $\mathrm{pH}$ 7.4. The sections were incubated with precisely diluted mouse monoclonal antibodies against Ki-67 (MIB-1predilutedDako, Japan) as primary antibodies for $1 \mathrm{~h}$ at $37^{\circ} \mathrm{C}$. Subsequently, after washing in TBS, the sections were incubated with a secondary antibody conjugated with peroxidase-labelled dextran polymers (Envision + Dual Link/HRP System, Dako) for $30 \mathrm{~min}$ at room temperature. After rinsing with TBS, they were treated with $0.5 \mathrm{mg} / \mathrm{ml} 3,3$ '-diaminobenzidine solution containing $0.001 \%$ hydrogen peroxide to visualize reaction products, and counterstained with Mayer's hematoxylin for $3 \mathrm{~min}$.

\section{Results}

Normal oral epithelium NOE $(n=10)$

The Ki-67 expression was detected in all cases of normal oral epithelium (NOE) and was restricted to the basal of the epithelium.

\section{Oral epithelial dysplasia (OED) $(n=30)$}

A- Mild oral epithelial dysplasia $(n=10)$

The Ki-67 expression was detected in all cases of mild OED and was located at the basal and parabasal layers of the epithelium.

B- moderate Oral epithelial dysplasia $(n=10)$

The Ki-67 expression was detected in all cases of moderate OED and was located at the basal, parabasal and spinous layers of the epithelium

C- severe Oral epithelial dysplasia $(n=10)$

Table 1. Immunohistochemical Quantitative Results for Ki-67 Protein in Oral Epithelial Dysplasia (OED), Oral Squamous Cell Carcinomas (OSCC), Normal Oral Epithelium (NOE)

\begin{tabular}{lccccc}
\hline Diagnosis & Mean Ki-67 & SD & SE & Min & Max \\
\hline NOE $(n=10)$ & 10.6 & 3.41 & 1.08 & 5 & 15 \\
OED $(n=30)$ & 36.83 & 19.56 & 3.57 & 10 & 75 \\
OSCC $(n=30)$ & 42.87 & 17.99 & 3.28 & 15 & 75 \\
\hline
\end{tabular}

Table 2. Bonferroni Test has been Used to Investigate a Binary Comparison between Groups

\begin{tabular}{|c|c|c|c|c|c|}
\hline $\begin{array}{l}\text { Sample } \\
1\end{array}$ & $\begin{array}{c}\text { Sample } \\
2\end{array}$ & $\begin{array}{c}\text { Mean } \\
\text { Difference }\end{array}$ & SD & $\begin{array}{c}P \\
\text { value }\end{array}$ & Differentiation \\
\hline $\begin{array}{l}\text { OED } \\
\text { group }\end{array}$ & $\mathrm{NOE}$ & 26.23 & 6.4 & 0 & $\begin{array}{l}\text { Significant } \\
\text { differences }\end{array}$ \\
\hline $\begin{array}{l}\text { OSCC } \\
\text { group }\end{array}$ & NOE & 32.27 & 6.4 & 0 & $\begin{array}{l}\text { Significant } \\
\text { differences }\end{array}$ \\
\hline $\begin{array}{l}\text { OED } \\
\text { group }\end{array}$ & $\begin{array}{l}\text { OSCC } \\
\text { group }\end{array}$ & -6.03 & 4.53 & 0.561 & $\begin{array}{c}\text { No Significant } \\
\text { differences }\end{array}$ \\
\hline
\end{tabular}

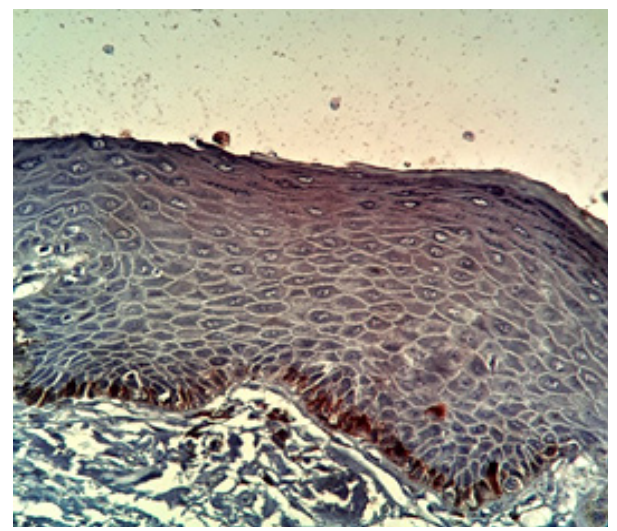

Figure 1. T he Nuclear Ki-67 Positivity was Found in the Basal of the Epithelium

The Ki-67 expression was detected in all cases of severe OED and was located at the basal, parabasal and spinous layers of the epithelium.

oral squamous cell carcinoma (OSCC) $(n=30)$

A- well-differentiated OSCC $(n=10)$

The Ki-67 expression was detected in all cases of welldifferentiated OSCC and was located at the periphery of the tumor nests than the centre.

B- moderately -differentiated OSCC $(n=10)$

The Ki-67 expression was detected in all cases of moderately-differentiated OSCC and was located at the periphery of the tumor nests and part of the centre.

C- poorly-differentiated OSCC $(n=10)$

The Ki-67 expression was detected in all cases of moderately-differentiated OSCC and was located at the

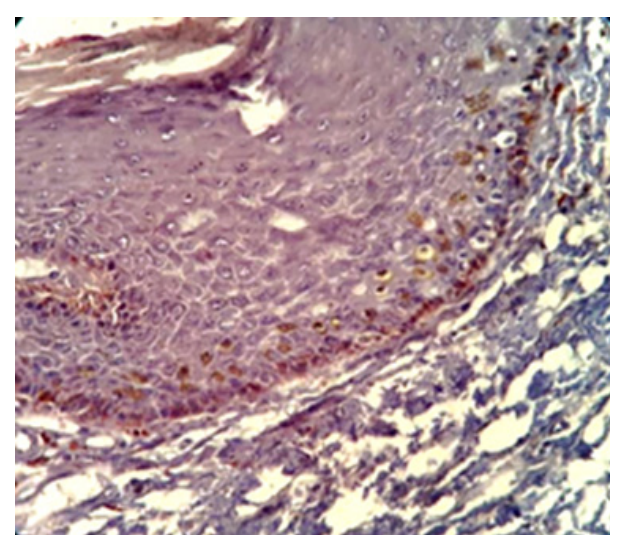

Figure 2. The Nuclear Ki-67 Positivity was Found in the Basal and Parabasal Layers of the Epithelium

Asian Pacific Journal of Cancer Prevention, Vol 19 
Table 3. Bonferroni Test has been Used to Investigate a Binary Comparison between Subgroups

\begin{tabular}{lccccc}
\hline Sample 1 & Sample 2 & Mean Difference & SD & P value & Differentiation \\
\hline mild OED & NOE (as control) & 6.2 & 2.67 & 0.157 & No Significant differences \\
moderate OED & NOE (as control) & 22.3 & 2.67 & 0 & Significant differences \\
severe OED & NOE (as control) & 50.2 & 2.67 & 0 & Significant differences \\
well-differentiated OSCC & NOE (as control) & 12.7 & 2.50 & 0 & Significant differences \\
moderately -differentiated OSCC & NOE (as control) & 30.6 & 2.50 & 0 & Significant differences \\
poorly-differentiated OSCC & NOE (as control) & 53.5 & 2.50 & 0 & Significant differences \\
\hline
\end{tabular}

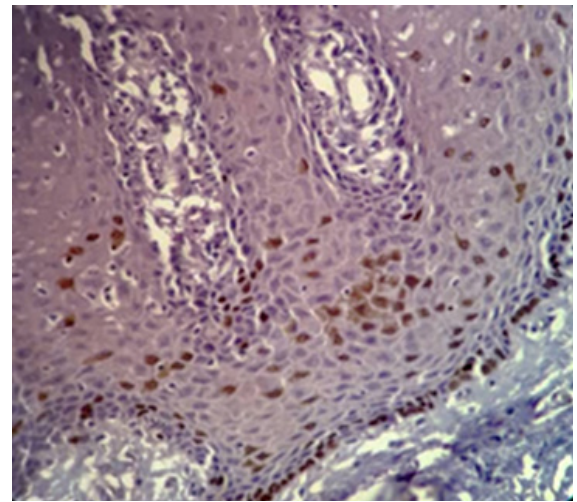

Figure 3. The Nuclear Ki-67 Positivity was Found in the Basal, Parabasal and Some of the Spinous Layers of the Epithelium

periphery of the tumor nests and most of the center.

\section{Statistical analysis}

All immunohistochemical slides were examined for positive staining by light microscopy. The mean percentage of positively stained cells was estimated by counting 300 cells per area from at least five varied areas representative of the lesion's histology. The nuclear expression of Ki-67 was counted according to epithelial layers as the basal layer, parabasal layer, and suprabasal layer using a microscope at $\times 400$.

The results were computed and subjected to statistical analysis using One-way ANOVA test and Bonferroni test. statistical comparison of Ki-67 protein expression in Oral epithelial dysplasia group, oral squamous cell carcinomas group and normal oral epithelium (NOE) revealed a

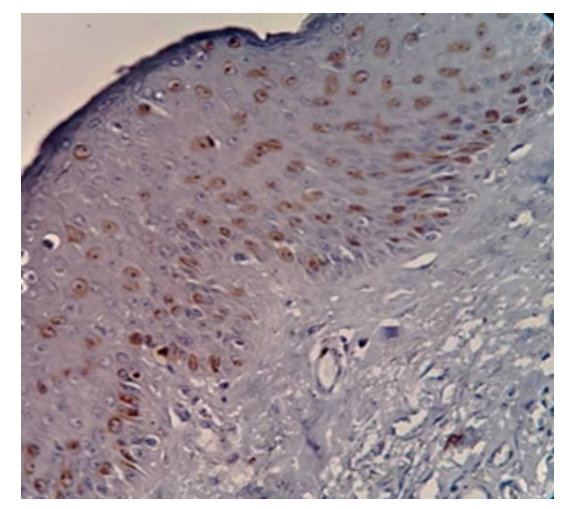

Figure 4. The Nuclear Ki-67 Positivity was Found in the Basal, Parabasal and Most of Spinous Layers of the Epithelium

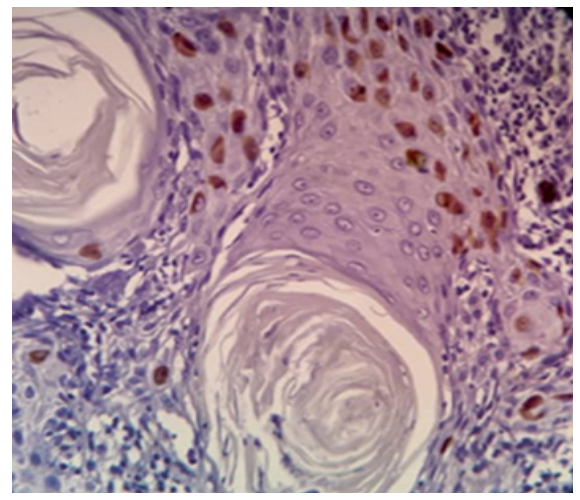

Figure 5. The Nuclear Ki-67 Positivity was Found in the Peripheral Area of Tumor Islands

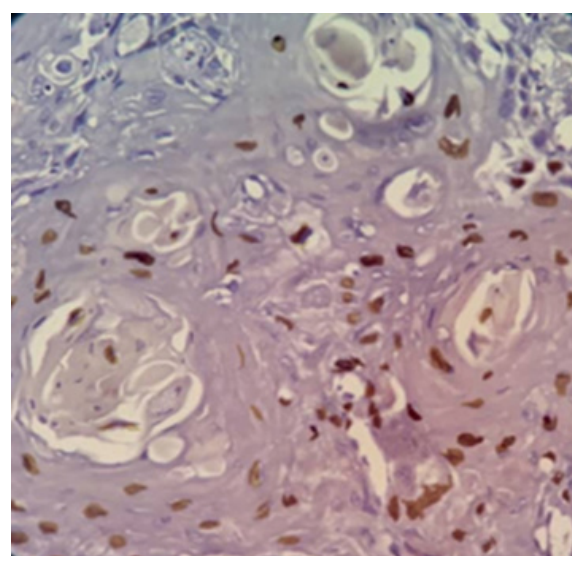

Figure 6. The Nuclear Ki-67 Positivity was Found in the Peripheral Area and Part of the Centerarea of Tumor Islands

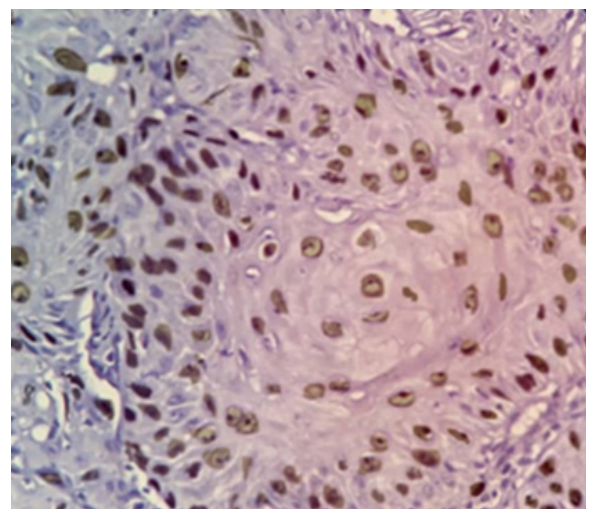

Figure 7. The Nuclear Ki-67 Positivity was Found in the Peripheral Area and Most of Centerarea of Tumor Islands 


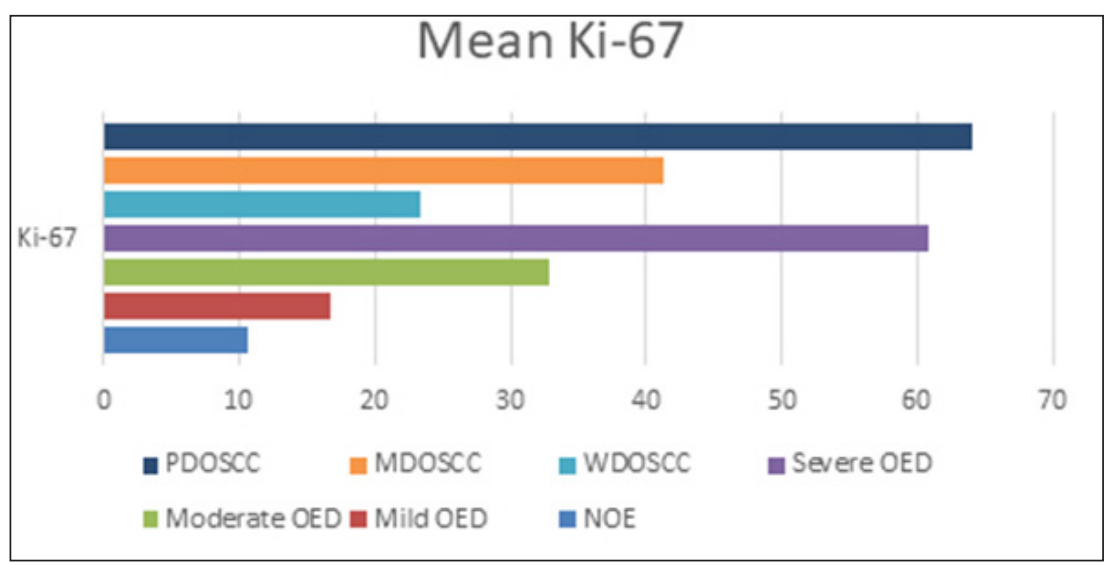

Figure 8. Graphical Demonstration of Immunohistochemical Quantitative Results of the Ki-67 Protein in the Study Sample. NOE, normal oral epithelium; OED, oral epithelial dysplasia; PDOSCC, poorly differentiated oral squamous cell carcinomas; MDOSCC, moderately differentiated oral squamous cell carcinomas; WDOSCC, well differentiated oral squamous cell carcinomas.

Significant difference, $\mathrm{P}=0.000$.

Data are expressed as the means of percentage of positive cells $95 \%$ confidence intervals. The expression of the Ki-67 protein in the various lesions was analyzed for significance using one-way ANOVA test to compare the mean Ki-67 protein among various study groups, a $\mathrm{P}$-value of $<0.05$ indicated a significant difference.

Statistical analysis indicates significant differences between the expression in moderate OED, severe OED, and NOE, showed 'P' value of 0.000 , the difference was not statistically significant between NOE and Mild OED group $(\mathrm{P}>0.05)$, we conclude that the rate of malignant transformation is higher in lesions that demonstrate moderate to severe dysplasia.

Statistical analysis indicated significant differences between the expression in well-differentiated OSCC group, moderately -differentiated OSCC group, poorly-differentiated OSCC group, and NOE showed 'P' value of 0.000 , we conclude from that the expression of $\mathrm{Ki}-67$ increased progressively according to the grades of OSCC.

\section{Discussion}

The transition of the normal oral epithelium to dysplasia and to malignancy is featured by increased cell proliferation (Dwivedi et al., 2013). The control on cell proliferation is thought to be impeded in cancer, and many studies have reported that abnormal cell proliferation appears to be a precursor as well as a predictor of tumorigenesis (Bacchi and Gown, 1993). As epithelial dysplasia is characterized by the number of cells and tissue alterations at a molecular and genetic level, there is an alteration of the cellular maturation in the epithelium leading increasing in the proliferative activity of the suprabasal layer (Kumar et al., 2015). Proliferative activity in oral epithelial dysplasia and oral squamous cell carcinomas can be determined by immunohistochemistry using antibodies reactive against various proliferating cellular antigens. Cell proliferation markers play an important role in the biological behavior of neoplasms (Watanabe et al., 2010). Discovery of various proliferation markers has enabled the detection of the hyperactive state of the epithelium and has been suggested to be of prognostic significance (Pitiyage et al., 2009).

The Ki-67 monoclonal antibody is commonly used and is reactive against the nuclear antigen $\mathrm{Ki}-67$ that is expressed during cell cycle phases $\mathrm{G} 1, \mathrm{~S}, \mathrm{G} 2$, and M but is not found during G0 (Prayson, 2005). The monoclonal antibody Ki-67 was first described in 1983 and suggested that it might be used as a marker for proliferating cells (Ross and Hall, 1995). A number of diagnostic applications for Ki-67 protein have been described, where Ki-67 was significantly more highly expressed in malignant than in normal tissues (Hu et al., 2012).

The significance of $\mathrm{Ki}-67$ protein as a prognostic marker has been widely studied, Ki-67 represents an additional predictor of survival in breast cancer (Pérez-López et al., 2016) cervical and uterine cancer, nonHodgkin's lymphoma and large bowel cancer (Palmqvist et al., 1999), (Kimura et al., 2000), and the expression of Ki67 can be used as a prognostic biomarker in Colorectal cancer (CRC) (Melling et al., 2016). Furthermore, Ki-67 is considered to be one of the best predictors of survival (Wang et al., 2009) and recurrence (Wangsa et al., 2008).

Increasing evidence indicates that $\mathrm{Ki}-67$ protein as a prognostic marker. It, therefore, merits further development and study. In this study, the expression of the cell cycle-associated protein Ki-67 was examined by immunohistochemistry in oral epithelial dysplasia (OED), oral squamous cell carcinomas (OSCC), normal oral epithelium (NOE) as a control. And this article reviews the significance of ‘ $\mathrm{Ki}-67$ protein as markers in diagnosis and prognostic assessment of severity of OED and histological grades of OSCC.

The mean Ki-67 protein was 10.60 for NOE, 16.80 for mild OED, 32.90 for moderate OED, 60.80 for severe OED, 23.3 for well-differentiated OSCC, 41,2 for moderately -differentiated OSCC, 64,1 for poorly-differentiated OSCC and 11,3 for normal oral epithelium.

In normal oral epithelium, the proliferating cells were restricted mainly in the basal layer of the epithelium this was in accordance with previous studies (Saito et al., 1999; Birajdar et al., 2014; Kumar et al., 2015). 
In our study, we found to that expression of the Ki-67 protein in the located at the basal, parabasal and spinous layers of the epithelium of OED and its expression increased with the severity of dysplasia This was in accordance with previous studies (Gonzalez-Moles et al., 2000; Dwivedi et al., 2013; Kumar et al., 2015).

The rate of malignant transformation may depend on the degree of dysplasia, and lesions that harbor high grade of dysplasia may be 4.5-times more likely to undergo such change when compared with mildly dysplastic lesions (Liu et al., 2010).

In the mild OED, the maximum expression of $\mathrm{Ki}-67$ was located at the basal and parabasal layers of the epithelium, which showed the least expression. As there was no statistically significant difference between the mild OED and the NOE, it can be concluded that it is very difficult to predict the prognosis of mild OED lesions, as it is more or less, not very aggressive and has proliferative activity similar to normal epithelium.

In the moderate OED, The nuclear Ki-67 positivity was found in the basal, parabasal and some of the spinous layers of the epithelium. There was the statistically significant difference between the moderate OED and the NOE, and in the severe OED the nuclear Ki-67 positivity was found in the basal, parabasal and most of spinous layers of the epithelium it can be concluded that it is the rate of malignant transformation is higher in lesions that demonstrate moderate to severe dysplasia. In future, the Ki-67 protein may serve as prognostic tools in the detection of malignant transformation in oral epithelial dysplasia.

And we found to that cell proliferation in OSCC increasing according to histological grades by an antibody for $\mathrm{Ki}-67$ protein this was in accordance with previous studies (Tumuluri et al., 2002; Dwivedi et al., 2013).

In well-differentiated OSCC the nuclear Ki-67 positivity was found in the peripheral area of tumor islands. This suggests that less differentiated cells are located in the peripheral layer and the central cells are highly differentiated with the ability of keratinization, thus, no expression of Ki-67 was observed in the central cells of the tumor island.

In moderately-differentiated OSCC, the nuclear Ki-67 positivity was found in the peripheral area and part of the centerarea of tumor islands. The overall staining of Ki-67 in moderately-differentiated OSCC was more quantitatively than well-differentiated OSCC.

In poorly-differentiated OSCC the nuclear Ki-67 positivity was found in the peripheral area and most of the centerarea of tumor islands the staining of Ki-67 was diffuse, it can be concluded that the cells were less differentiated and in more proliferating phase.

The high expression of the $\mathrm{Ki}-67$ protein in oral squamous cell carcinoma tissues may play an important role in the development of oral squamous cell carcinoma (He et al., 2015). Ki-67 protein increase with decreasing tissue differentiation of OED and OSCC.

The difference between OED and OSCC was not significant thereby signifying the fact that dysplastic epithelium holds a high potential for malignant transformation.
Because of expression Ki-67 protein in all proliferating cells and the prognostic value of the Ki-67 marker in many cancers, $\mathrm{Ki}-67$ protein is a potential therapeutic target in cancer, and strategies that inactivate $\mathrm{Ki}-67$ protein are a promising anti-proliferative approach, with potential applicability in cancer treatment (Kausch et al., 2003).

In conclusion, the cell proliferation in Oral epithelial dysplasia and oral squamous cell carcinomas can be determined by its growth rate using anti-Ki-67 monoclonal antibody.

The nuclear protein $\mathrm{Ki}-67$ is an established prognostic and predictive marker for the assessment of biopsies from patients with oral epithelial dysplasia and oral squamous cell carcinoma. The Ki-67 expression is significantly higher in tissues with moderately -differentiated or poorly differentiated squamous cell carcinoma and moderate or severe Oral epithelial dysplasia and provides an objective criterion for determining the severity of OED and histological grading of OSCC.

\section{Acknowledgements}

We want to declare that all laboratory tests were held at the Department of oral histology and pathology, Faculty of Dentistry, Damascus University. Damascus University has founded the entire project.

\section{References}

Bacchi C, Gown A (1993). Detection of cell proliferation in tissue sections. Braz J Med Biol Res, 26, 677-87.

Birajdar SS, Radhika M, Paremala K, et al (2014). Expression of $\mathrm{Ki}-67$ in normal oral epithelium, leukoplakic oral epithelium and oral squamous cell carcinoma. JOral Maxillofac pathol, 18, 169.

Boeve K, Schepman KP, Schuuring E, et al (2018). High sensitivity and negative predictive value of sentinel lymph node biopsy in a retrospective early stage oral cavity cancer cohort in the Northern Netherlands. Clin Otolaryngol, 18, 89.

Booth DG, Earnshaw WC (2017). Ki-67 and the chromosome periphery compartment in mitosis. Trends Cell Biol, 5, 458.

Conway C, Graham JL, Chengot P, et al (2015). Elucidating drivers of oral epithelial dysplasia formation and malignant transformation to cancer using RNAseq. Oncotarget, 6, 40186.

Dowsett M, Nielsen TO, A'Hern R, et al (2011). Assessment of Ki67 in breast cancer: recommendations from the International Ki67 in Breast Cancer working group. JNCI, 103, 1656-64.

Dwivedi N, Chandra S, Kashyap B, et al (2013). Suprabasal expression of Ki-67 as a marker for the severity of oral epithelial dysplasia and oral squamous cell carcinoma. Contemp clin dent, $4,7$.

Feller L, Lemmer J (2012). Oral squamous cell carcinoma: epidemiology, clinical presentation and treatment. J Cancer Ther, 3, 263.

Gavish A, Krayzler E, Nagler R (2016). Tumor growth and cell proliferation rate in human oral cancer. Arch Med Res, 47, 271-4.

Gerdes J, Schwab U, Lemke H, et al (1983). Production of a mouse monoclonal antibody reactive with a human nuclear antigen associated with cell proliferation. Int J Cancer, $\mathbf{3 1}$, 13-20.

Gonzalez-Moles MA, Ruiz-Avila I, Rodriguez-Archilla A, et al 
(2000). Suprabasal expression of Ki-67 antigen as a marker for the presence and severity of oral epithelial dysplasia. Head Neck, 22, 658-61.

He W, Xiao Y, Chen W (2015). Expression of Ki-67 and P53 protein in oral squamous cell carcinoma and its clinical significance. Shanghai J Stomatol, 24, 228-31.

Ho M, Risk J, Woolgar J, et al (2012). The clinical determinants of malignant transformation in oral epithelial dysplasia. Oral Oncol, 48, 969-76.

Hooghe B, Hulpiau P, Van Roy F, et al (2008). ConTra: a promoter alignment analysis tool for identification of transcription factor binding sites across species. Nucleic Acids Res, 36, 128-32.

Hu H-Y, Liu H, Zhang J-W, et al (2012). Clinical significance of Smac and Ki-67 expression in pancreatic cancer. Hepatogatroenterology, 59, 2640-3.

Hwang JTK, Gu YR, Dickson BJ, et al (2018). RETRACTED: Straticyte demonstrates prognostic value over oral epithelial dysplasia grade for oral potentially malignant lesion assessment. Oral Oncol, 77, 138.

Ishihara M, Mukai H, Nagai S, et al (2013). Retrospective analysis of risk factors for central nervous system metastases in operable breast cancer: effects of biologic subtype and Ki67 overexpression on survival. Oncology, 84, 135-40.

Jeon JH, Kim MG, Park JY, et al (2017). Analysis of the outcome of young age tongue squamous cell carcinoma. Maxillofac Plast Reconstr Surg, 39, 41.

Josefsson A, Wikström P, Egevad L, et al (2012). Low endoglin vascular density and Ki67 index in Gleason score 6 tumours may identify prostate cancer patients suitable for surveillance. Scand J Urol Nephrol, 46, 247-57.

Kausch I, Lingnau A, Endl E, et al (2003). Antisense treatment against Ki-67 mRNA inhibits proliferation and tumor growth in vitro and in vivo. Int $J$ Cancer, 105, 710-6.

Khammissa R, Meer S, Lemmer J, et al (2014). Oral squamous cell carcinoma in a South African sample: Race/ethnicity, age, gender, and degree of histopathological differentiation. J Cancer Res Ther, 10, 908.

Kimura T, Tanaka S, Haruma K, et al (2000). Clinical significance of MUC1 and E-cadherin expression, cellular proliferation, and angiogenesis at the deepest invasive portion of colorectal cancer. Int J Oncol, 16, 55-119.

Kumar A, Cascarini L, McCaul JA, et al (2013). How should we manage oral leukoplakia?. Br J Oral Maxillofac Surg, 51, 377-83.

Kumar KV, Chaithanya K, Punde P, et al (2015). Comparative evaluation of imunohistochemical expression of $\mathrm{Ki}-67$ in oral lichen planus, oral leukoplakia and normal mucosa cases. J Int Oral Health, 7, 82.

Li LT, Jiang G, Chen Q, et al (2015). Ki67 is a promising molecular target in the diagnosis of cancer. Mol Med Rep, 11, 1566-72.

Liang H, Yang Z, Wang JB, et al (2017). Association between oral leukoplakia and risk of upper gastrointestinal cancer death: A follow-up study of the Linxian General Population Trial. Thorac Cancer, 8, 642-8.

Liu W, Wang Y-F, Zhou H-W, et al (2010). Malignant transformation of oral leukoplakia: a retrospective cohort study of 218 Chinese patients. BMC Cancer, 10, 685.

MacCallum DE, Hall PA (2000). The location of pKi67 in the outer dense fibrillary compartment of the nucleolus points to a role in ribosome biogenesis during the cell division cycle. J Pathol, 190, 537-44.

Malecki K, Glinski B, Mucha-Malecka A, et al (2012). Predictive and prognostic value of p53, Ki-67 and EGFR in patients with advanced oral cavity and oropharyngeal cancer treated with induction chemotherapy. Przegl Lek, 69, 5-8.
Melling N, Kowitz CM, Simon R, et al (2016). High Ki67 expression is an independent good prognostic marker in colorectal cancer. J Clin Pathol, 69, 209-14.

Modlin IM, Moss SF, Chung DC, et al (2008). Priorities for improving the management of gastroenteropancreatic neuroendocrine tumors. $J$ Natl Cancer Inst, 100, 1282-9.

Monteiro de Oliveira Novaes JA, William WN Jr (2016). Prognostic factors, predictive markers and cancer biology: the triad for successful oral cancer chemoprevention. Future Oncol, 12, 2379-86.

Muller S (2018). Oral epithelial dysplasia, atypical verrucous lesions and oral potentially malignant disorders: focus on histopathology. Oral Surg Oral Med Oral Pathol Oral Radiol, 125, 591-602.

Mutalik S, Mutalik VS, Pai KM, et al (2014). Oral leukoplakia - is biopsy at the initial appointment a must?. J Clin Diagn Res, 8, ZC04-7.

Nagao T, Warnakulasuriya S, Sakuma H, et al (2017). p53 and ki67 as biomarkers in determining response to chemoprevention for oral leukoplakia. J Oral Pathol Med, 46, 346-52.

Palmqvist R, Sellberg P, Öberg Å, et al (1999). Low tumour cell proliferation at the invasive margin is associated with a poor prognosis in Dukes' stage B colorectal cancers. Br J Cancer, 79, 577.

Panwar A, Lindau R, Wieland A (2014). Management for premalignant lesions of the oral cavity. Expert Rev Anticancer Ther, 14, 349-57.

Pérez-López M, García-Gómez J, Alves M, et al (2016). Ki-67 is a prognostic marker for hormone receptor positive tumors. Clin Translat Oncol, 18, 996-1002.

Pindborg J, Renstrup G, Poulsen H, et al (1963). Studies in oral leukoplakias. V. Clinical and histologic signs of malignancy. Acta Odontol Scand, 21, 407-14.

Pitiyage G, Tilakaratne W, Tavassoli M, et al (2009). Molecular markers in oral epithelial dysplasia. J Oral Pathol Med, 38, 737-52.

Prayson RA(2005). The utility of MIB-1/Ki-67 immunostaining in the evaluation of central nervous system neoplasms. $A d v$ Anat Pathol, 12, 144-8.

Rahaman SMU, Mujib BA (2014). Histopathological correlation of oral squamous cell carcinoma among younger and older patients. J Oral Maxillofac Surg Med Pathol, 18, 183.

Rajendran R (2006). Benign and malignant tumors of the oral cavity. Shafer's Textbook of Oral Pathology, 6, pp 169-73.

Rhodus NL, Kerr AR, Patel K (2014). Oral cancer: leukoplakia, premalignancy, and squamous cell carcinoma. Dent Clin, $\mathbf{5 8}, 315-40$

Ross W, Hall P (1995). Ki67: from antibody to molecule to understanding?. Clin Mol Pathol, 48, M113.

Saito T, Nakajima T, Mogi K (1999). Immunohistochemical analysis of cell cycle-associated proteins $\mathrm{p} 16, \mathrm{pRb}, \mathrm{p} 53, \mathrm{p} 27$ and Ki-67 in oral cancer and precancer with special reference to verrucous carcinomas. J Oral Pathol Med, 28, 226-32.

Sasaki T, Moles D, Imai Y, et al (2005). Clinico-pathological features of squamous cell carcinoma of the oral cavity in patients $<40$ years of age. J Oral Pathol Med, 34, 129-33.

Scholzen T, Gerdes J (2000). The Ki-67 protein: from the known and the unknown. J Cell Physiol, 182, 311-22.

Scully C (2000). Oral health in America: a report of the surgeon general. J Oral Pathol Med, 23, 59.

Shirendeb U, Hishikawa Y, Moriyama S, et al (2009). Human papillomavirus infection and its possible correlation with p63 expression in cervical cancer in Japan, Mongolia, and Myanmar. Acta Histochem Cytochem, 42, 181-90.

Sorbye SW, Kilvaer TK, Valkov A, et al (2012). Prognostic impact of Jab1, p16, p21, p62, Ki67 and Skp2 in soft tissue 
sarcomas. PLoS One, 7, e47068.

Takagi M, Natsume T, Kanemaki MT, et al (2016). Perichromosomal protein Ki67 supports mitotic chromosome architecture. Genes Cells, 21, 1113-24.

Tumuluri V, Thomas G, Fraser I (2002). Analysis of the Ki-67 antigen at the invasive tumour front of human oral squamous cell carcinoma. J Oral Pathol Med, 31, 598-604.

van der Waal I (2018). Historical perspective and nomenclature of potentially malignant or potentially premalignant oral epithelial lesions with emphasis on leukoplakia-some suggestions for modifications. Oral Surg Oral Med Oral Pathol Oral Radiol, 125, 577-81.

Vigneswaran N, Williams MD (2014). Epidemiologic trends in head and neck cancer and aids in diagnosis. Oral Maxillofac Surg Clin North Am, 26, 123-41.

Wang B, Zhang S, Yue K, et al (2013). The recurrence and survival of oral squamous cell carcinoma: a report of 275 cases. Chin J Cancer, 32, 614-8.

Wang Z, Zhang B, Jiang L, et al (2009). RACK1, an excellent predictor for poor clinical outcome in oral squamous carcinoma, similar to Ki67. Eur J Cancer, 45, 490-6.

Wangsa D, Ryott M, Åvall-Lundqvist E, et al (2008). Ki-67 expression predicts locoregional recurrence in stage I oral tongue carcinoma. Br J Cancer, 99, 1121.

Warnakulasuriya S, Johnson N, Van der Waal I (2007). Nomenclature and classification of potentially malignant disorders of the oral mucosa. J Oral Pathol Med, 36, 575-80.

Warnakulasuriya S, Reibel J, Bouquot J, et al (2008). Oral epithelial dysplasia classification systems: predictive value, utility, weaknesses and scope for improvement. J Oral Pathol Med, 37, 127-33.

Watanabe S, Watanabe R, Oton-Leite AF, et al (2010). Analysis of cell proliferation and pattern of invasion in oral squamous cell carcinoma. J Oral Sci, 52, 417-24.

Whitfield ML, George LK, Grant GD, et al (2006). Common markers of proliferation. Nat Rev Cancer, 6, 99.

Yerushalmi R, Woods R, Ravdin PM, et al (2010). Ki67 in breast cancer: prognostic and predictive potential. Lancet Oncol, 11, 174-83.

Zaid KW (2014). Immunohistochemical assessment of E-cadherin and beta-catenin in the histological differentiations of oral squamous cell carcinoma. Asian Pac J Cancer Prev, 15, 8847-53.

Zaid KW, Chantiri M, Bassit G (2016). Recombinant human bone morphogenetic protein-2 in development and progression of oral squamous cell carcinoma. Asian Pac J Cancer Prev, 17, 927-32.

\section{ब요}

This work is licensed under a Creative Commons AttributionNon Commercial 4.0 International License. 